\title{
Environmental risk assessment of genetically modified plants - concepts and controversies
}

\author{
Angelika Hilbeck ${ }^{1 *}$, Matthias Meier², Jörg Römbke ${ }^{3}$, Stephan Jänsch ${ }^{3}$, Hanka Teichmann ${ }^{4}$, Beatrix Tappeser ${ }^{4}$
}

\begin{abstract}
Background and purpose: In Europe, the EU Directive 2001/18/EC lays out the main provisions of environmental risk assessment (ERA) of genetically modified (GM) organisms that are interpreted very differently by different stakeholders. The purpose of this paper is to: (a) describe the current implementation of ERA of GM plants in the EU and its scientific shortcomings, (b) present an improved ERA concept through the integration of a previously developed selection procedure for identification of non-target testing organisms into the ERA framework as laid out in the EU Directive 2001/18/EC and its supplement material (Commission Decision 2002/623/EC), (c) describe the activities to be carried out in each component of the ERA and (d) propose a hierarchical testing scheme. Lastly, we illustrate the outcomes for three different crop case examples.
\end{abstract}

Main features: Implementation of the current ERA concept of GM crops in the EU is based on an interpretation of the EU regulations that focuses almost exclusively on the isolated bacteria-produced novel proteins with little consideration of the whole plant. Therefore, testing procedures for the effect assessment of GM plants on non-target organisms largely follow the ecotoxicological testing strategy developed for pesticides. This presumes that any potential adverse effect of the whole GM plant and the plant-produced novel compound can be extrapolated from testing of the isolated bacteriaproduced novel compound or can be detected in agronomic field trials. This has led to persisting scientific criticism.

Results: Based on the EU ERA framework, we present an improved ERA concept that is system oriented with the GM plant at the centre and integrates a procedure for selection of testing organisms that do occur in the receiving environment. We also propose a hierarchical testing scheme from laboratory studies to field trials and we illustrate the outcomes for three different crop case examples.

Conclusions and recommendations: Our proposed concept can alleviate a number of deficits identified in the current approach to ERA of GM plants. It allows the ERA to be tailored to the GM plant case and the receiving environment.

\section{Background and purpose}

In most countries of the world, genetically modified (GM) organisms are subject to regulation. In Europe and all countries that are signatories to the Cartagena Protocol, environmental risk assessment (ERA) is required for the regulatory approval of GM organisms (GMO) (CBD 2000, Annex II; 6; 1, Annex III) [1].

\section{Scientific requirements of ERA of GM plants in the European Union}

ERA as defined in the European Union (EU) legislation has to evaluate the 'risks to human health and the

\footnotetext{
* Correspondence: angelika.hilbeck@ecostrat.ch

${ }^{1}$ Ecostrat GmbH, 8032 Zurich, Hottingerstrasse 32, Zurich, 8032, Switzerland Full list of author information is available at the end of the article
}

environment, whether direct or indirect, immediate or delayed, which the deliberate release or the placing on the market of GMOs may pose' (EC 2001, Annex II) [2]. In addition, potential cumulative long-term effects have to be analysed. The EU Directive 2001/18 (EC 2001, Annex II) [2] further describes the different 'effect categories' to be considered. 'Direct effects' are primary effects on human health and the environment which are the result of the GMO itself and which do not occur through a causal chain of events. 'Indirect effects' are effects 'occurring through a causal chain of events, through mechanisms such as interactions with other organisms, transfer of genetic material, or changes in use or management of the crop' (EC 2001, Annex II) [2]. 'Immediate effects' refer to effects 'which are

\section{SpringerOpen ${ }^{\circ}$}

(C) 2011 Hilbeck et al; licensee Springer. This is an Open Access article distributed under the terms of the Creative Commons Attribution License (http://creativecommons.org/licenses/by/2.0), which permits unrestricted use, distribution, and reproduction in any medium, provided the original work is properly cited. 
observed during the period of the release of the GMO. Immediate effects may be direct or indirect.' 'Delayed effects' are effects 'which may not be observed during the period of the release of the GMO but become apparent as a direct or indirect effect either at a later stage or after termination of the release' [2]. All this should be done on a case-by-case basis, in a stepwise fashion and properly consider uncertainty and knowledge gaps [2,3]. Last but not least, EU legislation states that 'The precautionary principle has been taken into account in the drafting of this directive and must be taken into account when implementing it' $[2,4]$. While these provisions give guidance, a heated debate persists just on how they should be interpreted, and, more importantly, implemented [5]. In our view, the current implementation of ERA falls short of complying with the EU regulations.

\section{Purpose}

The purpose of this paper is to address the following objectives: (a) to describe the current implementation of ERA of GM plants in the EU and its scientific shortcomings, (b) to present an improved ERA concept through the integration of a previously developed selection procedure for identification of non-target testing organisms into the ERA framework as laid out in the EU Directive 2001/18/EC [2] and its supplement material $[3,6]$, (c) to describe the activities to be carried out in each component of the ERA and (d) propose a hierarchical testing scheme. Lastly, we illustrate the outcomes for different crop case examples (Table 1).

\section{Current implementation of ERA of GM plants and its deficits}

The ERA of GM plants currently focuses only on the novel trait and the novel substance (e.g. Bt-toxins, see below) expressed therein (Table 1). This interpretation was precedented by the US regulations [7] and found support by corporate developers of GM plants and some governmental regulators of GM organisms in the US and Europe $[8,9]$. This current implementation of the regulations of GM plants is grounded in the concept of 'substantial equivalence' of GM plants and its non-transformed counterparts [10-12]. In order to demonstrate that a GM plant is substantially equivalent to the nontransformed parent plant, a number of basic compounds are measured and compared not only between the GM and non-GM cultivars but also to any published data of

Table 1 Comparison of current and alternative approaches to environmental risk assessment of genetically modified organisms

\begin{tabular}{|c|c|c|}
\hline & Current ERA model & Alternative ERA model \\
\hline Focus & $\begin{array}{l}\text { Novel trait = novel protein (pesticide model) as } \\
\text { separate singular component }\end{array}$ & GMO (novel protein is integral component) \\
\hline \multirow{3}{*}{$\begin{array}{l}\text { Stressor (characteristic causing } \\
\text { adverse effect) }\end{array}$} & Primary & Primary $(=\mathrm{GMO})$ \\
\hline & $=$ novel trait & $\begin{array}{l}\text { Secondary (any other measure required to realize } \\
\text { benefit and intended effect of GMO) }\end{array}$ \\
\hline & $=$ novel protein & \\
\hline \multirow[t]{3}{*}{ Test material } & Bacteria-produced and purified novel protein & Bacteria-produced and purified novel protein \\
\hline & Pollen & Pollen \\
\hline & & $\mathrm{GMO}$ \\
\hline \multicolumn{3}{|l|}{ Tested effects } \\
\hline Direct acute effects & Yes & Yes \\
\hline Direct chronic effects & $\begin{array}{l}\text { No, unless significant adverse direct effects at low } \\
\text { tier }\end{array}$ & Yes, for selected species \\
\hline Indirect effects & $\begin{array}{l}\text { No, unless significant adverse direct effects at low } \\
\text { tier }\end{array}$ & Yes, for selected species \\
\hline $\begin{array}{l}\text { Interaction effects with other } \\
\text { primary and secondary plant } \\
\text { compounds and/or the environment }\end{array}$ & $\begin{array}{l}\text { No, unless significant adverse direct effects at low } \\
\text { tier }\end{array}$ & Yes, for selected species \\
\hline Test organisms & $\begin{array}{l}\text { Standard set of universal testing species, } \\
\text { representative for trophic levels of a generic } \\
\text { ecosystem (i.e., first producer, first consumer, second } \\
\text { consumer, etc.) according to OECD [33] guidelines } \\
\text { for pesticide testing }\end{array}$ & $\begin{array}{l}\text { Procedure for case-specific selection of suitable testing } \\
\text { species, representative for important ecological } \\
\text { functions of the receiving environments }\end{array}$ \\
\hline Testing procedures & $\begin{array}{l}\text { Prescriptive regarding detailed standardised } \\
\text { experimental protocols according to OECD [33] } \\
\text { guidelines for pesticide testing }\end{array}$ & $\begin{array}{l}\text { Prescriptive regarding procedure to develop proper } \\
\text { risk hypotheses and derive relevant testing protocols } \\
\text { for the selected testing species }\end{array}$ \\
\hline
\end{tabular}


that plant species (e.g. any cultivar of maize including publications predating World War II) [13]. Typically, the measured compounds are amino acids, total protein, fatty acids, carbohydrates, and occasionally anti-nutrients like glucosinolate in oilseed rape or solanine in potato. Although OECD consensus documents on compositional considerations have been published for various crops, no mandatory guidelines exist regarding what to test and how similar the values should be in order to still comply with being 'equivalent'. Most importantly, the degree of difference between a nontransformed parent cultivar or any other cultivar of the same plant species and the GM event is not defined [14]. From personal experience of some of the authors of this article with data submitted in dossiers of GM plants seeking regulatory approval, these substantial equivalence data do frequently yield significant differences even outside of reported ranges for other (at times 'historic') cultivars but are then dismissed as 'biologically irrelevant'. The substantial equivalence (or familiarity) concept is therefore highly contested in particular with regard to its relevance for biosafety evaluations as it serves as the prime screen for unintended effects [14-16]. According to the developers of GM plants and some government regulators, the declaration of substantial equivalence legitimates to omit testing for anything but initial acute, short-term effects of the isolated bacteria-produced toxin $[8,9,17]$ : 'If [...] the only difference found between the GM plant and the nonGM comparator is the newly expressed protein(s), the risk assessment can focus on the potential effects of this protein(s)' $[8,9,12]$. Or: 'If the transgenic plant does not differ from its near isoline, the stressor that needs to be assessed is simply the introduced trait (e.g. the expressed Cry protein) and not the whole plant.' [12]. It is assumed that such initial tests using isolated bacteriaproduced surrogate proteins are sufficiently reliable indicators for the required assessment of 'indirect', 'delayed' and 'cumulative' effects of the whole GM organism, including interaction effects of any existing secondary compounds (e.g. glycoalkaloids, glucosinolates) with the expressed novel toxins. If these acute toxicity tests do not yield data of concern any further testing in the environment for broader and more long-term effects is deemed obsolete $[8,12]$. However, even for chemicals, this strategy is by no means uncontroversial [18-20]. For GM organisms, a further dimension of complexity arises. Not only is the lab-to-field extrapolation of the tested chemical debatable but, under the current approach, we additionally extrapolate from an isolated chemical surrogate (tested in the lab) to a complex living biological organism (in the field).

In practice, it also means that for GM plants that do not express a 'novel' pesticidal protein, as herbicide resistant (HR) crops or GM plants with altered primary compounds, like starch-altered GM crops, either no stressors are identified or their relevance is dismissed. This applies especially to the most widely used GM plants worldwide, HR crops. The vast majority of them are resistant to the broad spectrum herbicide glyphosate. The considered novel trait/protein (i.e. stressor) is a substitute enzyme from a microorganism (e.g. CP4 EPSPS conferring resistance to glyphosate) that is similar but not identical to the one naturally occurring in the conventional plants. It is in such significantly different as it enables the GM crop to continue the synthesis of essential amino acids which in non-GM plants is blocked by the corresponding broadspectrum herbicide - as a result, all plants except the HR crop die. However, for biosafety purposes, it is not considered a 'novel' compound and usually no testing for adverse effects of the whole GM plant is deemed necessary (Table 1). Occasionally, however, some toxicity tests with the new, again, bacteria-produced enzyme are performed. Based on this logic, the adverse effects of the broad-spectrum herbicide (on non-target flora and fauna and the evolution of resistant weeds) required to benefit from the technology, are excluded from the ERA [13,21]. Some ecotoxicological aspects are considered in the registration of the pesticide (typically only submitted as request for extension of current use) but are not submitted in the context of the ERA of the GMO. Consequently, it is also not taken into account that GM HR crops do now contain higher concentrations of residues of the applied systemic herbicide, like glyphosate and its metabolite AMPA, than under the conventional use of these herbicides [22-24]. Aside of the health issues associated with any pesticide residue in food and feed, these higher herbicide residues have also an associated ecotoxicological dimension with regard to input pathways, persistence and bioactivity of pesticide residues in the ecosystem, in addition to the herbicide residues resulting from the external application. Further ignored are any unintended changes in the activity pattern of both the novel and native enzymes produced in the GM plant. We argue that these are serious shortcomings of the current approach to ERA of GM plants and identify the urgent need for improvement.

\section{Proposal for a scientifically improved ERA concept complying with EU regulations}

We propose a scientifically improved ERA concept that places the whole GM organism at the centre of the assessment. This includes potential adverse effects arising from direct and indirect exposure to the whole GM plant and from secondary stressors that are required to realise the benefit and intended effect(s) of the GM plant, such as the application of broad spectrum herbicides (Table 1) [25]. 
In this paper, we present the following new aspects beyond and above previously published material: (a) we integrate the selection procedures for identification of non-target testing organisms into the ERA framework as outlined in the EU Directive 2001/18/EC [2] and supplemented by the Guidance Notes of the EU Commission 2002/623/EC [3] and (b) describe the activities to carried out in each component of the ERA. This will address the components I - IV which represent a risk assessment sensu strictu. Furthermore, we propose a hierarchical testing scheme. Moreover, we contrast the activities we propose to be carried out under the first three components of the ERA framework to those proposed following the currently applied approach to ERA in Table 1 in order to highlight the improvements. Lastly, we illustrate the outcomes for three different crop case examples.

The selection procedure which we integrate into the EU Directive ERA framework is the outcome of the 'GMO ERA Project' produced by an international group of scientists from the global working group 'Transgenic Organisms in IPM and Biocontrol' run under the auspices of the IOBC (International Organisation for Biological Control) [21,26-29] (Figure 1).

\section{Hazard identification - the scope of ERA}

In this first component of the ERA framework, EU legislation requires the 'identification of characteristics which may cause adverse effects' (Figure 1). This component is the most critical part of the ERA, as it is here where the scope of the ERA is determined.

\section{Defining the 'case'}

For an inclusive approach of ERA to be compliant with the EU regulations, it is reasonable to begin this process by defining and describing the 'case' to be assessed. This constitutes the basis for building the process in a systematic and transparent manner. Based on the provisions put forward by the Directive 2001/18/EC [2] and, similarly by the Cartagena Protocol on Biosafety [1], a case is described by the three elements: (1) the crop plant, (2) the novel trait relating to its intended effect and phenotypic characteristics of the GM plant and (3) the receiving environment relating to the intended use of the GM plant. For each element, information must be compiled and synthesised.

For the crop plant, any information on its biology, ecology and current spatio-temporal agronomic use and limitations of use is compiled. For the novel trait, this includes comprehensive information on the molecular characterization of the GM plant, its introduced genetic material and tissue-specific expression of the novel proteins. Information on the intended effect(s) include(s) for example all available data on the problem to be solved with the proposed GM plant, efficacy data of the GM plant demonstrating the ability to solve that problem, the severity of the problem, how widespread the problem is and who is mostly affected by the problem.

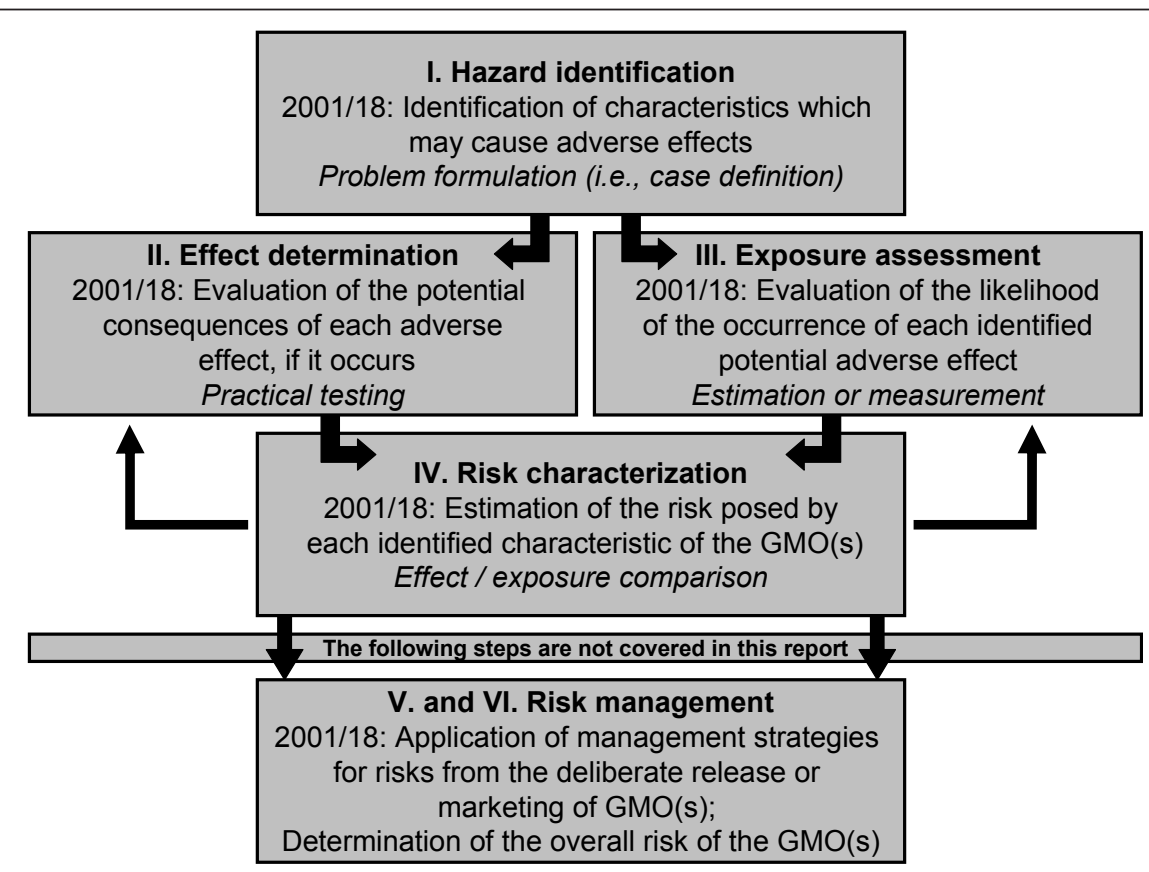

Figure 1 Components of ERA scheme as laid out in Commission Decision 2002/623/EC supplementing EU Directive 2001/18/EC. Proposed activities added in italics. 
To do that in an inclusive and transparent manner, scientists have developed a stakeholder process and tested it for the use in ERA of GM organisms [30,31]. This procedure was recently transformed into a practical guidance handbook [32]. Such a systematic process allows to identify the main users of the GM plant, and to estimate the potential adoption rate and spread of the GMO after release. This in turn allows to delineate the potential receiving environments and focus the analysis on those where the adoption is expected to be greatest with the assumption that potential adverse environmental effects will likely manifest firstly and foremost where the GM crop is grown most frequently and most widespread. Finally, the identification of the potential receiving environments is essential to characterise the existing biodiversity and ecological processes that might be affected and from which the candidate testing species will be selected (see next section).

\section{What species to test?}

Under the current ERA model, ecotoxicological testing follows closely the methodologies developed for environmental chemicals like pesticides [33]. These are prescriptive with regard to the testing organisms and detailed testing protocols. Testing organisms are chosen from a list of universal standard species that are representative for trophic levels in general rather than present in a given receiving environment (Table 1) [25].

Our proposed methodology for testing of non-target organisms is prescriptive with regard to the use of a procedure for selection of testing species and the development of proper testing protocols and risk hypotheses tailored to each case and receiving environment. This procedure was developed and tested for three case examples by the 'GMO ERA Project', for detailed description of the selection procedure and outcomes of the test run see the series of publications by $[28,27,34,35]$. Here, we only provide a brief summary (Figure 2).

The selection procedure is a step-wise process that begins with identifying the most important ecological functions relevant to the sustainable production of the GM plant (Figure 2). Based on the information obtained from the characterization of the existing biodiversity in the identified receiving environments, a list of the most relevant functional groups for the given cropping system is compiled and the identified species are classified according to their known ecological functions (Step 1, Figure 2). Next, a defined set of ecological criteria is used to select the most important species of each functional category. Each species is ranked according to its geographic distribution, habitat specialization, abundance, phenology, linkage and association with the crop (Step 2, Figure 2). As this step is largely independent of the genetically engineered novel trait of the crop plant, the outcome of these two steps can be used for ERA of other GM, cases using the same plant/crop species. The goal is to select those species that rank highest in these ecological criteria and, therefore, have an important functional role in that cropping system. The rationale is that if these species are adversely affected by a GM plant, it could indeed result in an adverse environmental effect. These two selection steps greatly reduce the number of potential testing species existing in a given cropping system and surrounding habitats while acknowledging the limitations of the available knowledge about species and their function and identifying important gaps of information. Only those candidate species that were ranked highest in these two preceding steps are taken further along in the procedure. The goal is that neither all nor too little is required for testing but a reasonable set of species with greatest relevance to the receiving environment and an important ecological function in the given cropping system. The outcome of this first critical component is the scope and context of the ERA and the testing strategy tailored to the particular GM plant case in its receiving environment.

\section{Exposure assessment - from pathways to scenarios and protocols}

For the species ranked highest in the previous component, an exposure analysis is conducted to determine whether or not and to what degree the species come into contact with the primary stressor, i.e. the GM plant including the transgene product (e.g. a Bt-toxin) or the altered composition of primary metabolic compounds (e.g. starch), or any secondary stressor required for realizing the transgenic function of the GMP, e.g. the broad spectrum herbicide for HR GM plants (step 3, Figure 2). Because the respective transgene products are integral parts of the GM plants and their expression is coupled to the physiology and metabolism of the plant, exposure of associated organisms can be multi-fold and complex. Exposure can be bitrophic via the GM plant including any metabolites of the transgene products in residues, fluids (e.g. phloem) or secretions (e.g. nectar, root exudates). Exposure of higher order consumers can occur through multitrophic exposure routes when the transgene products move through the food web. Also, after movement and expression of the transgenes in other genetic contexts (e.g. wild relatives), an entirely different suite of organisms can get into contact with the novel transgene products. The same holds true after spread of the transgene products, such as the Bt-toxin including any metabolites, away from the field of release of the GM plant e.g. embedded in wind dispersed GM pollen or in GM plant residue washed into water systems like ponds, lakes, creeks and rivers, or leaching of 


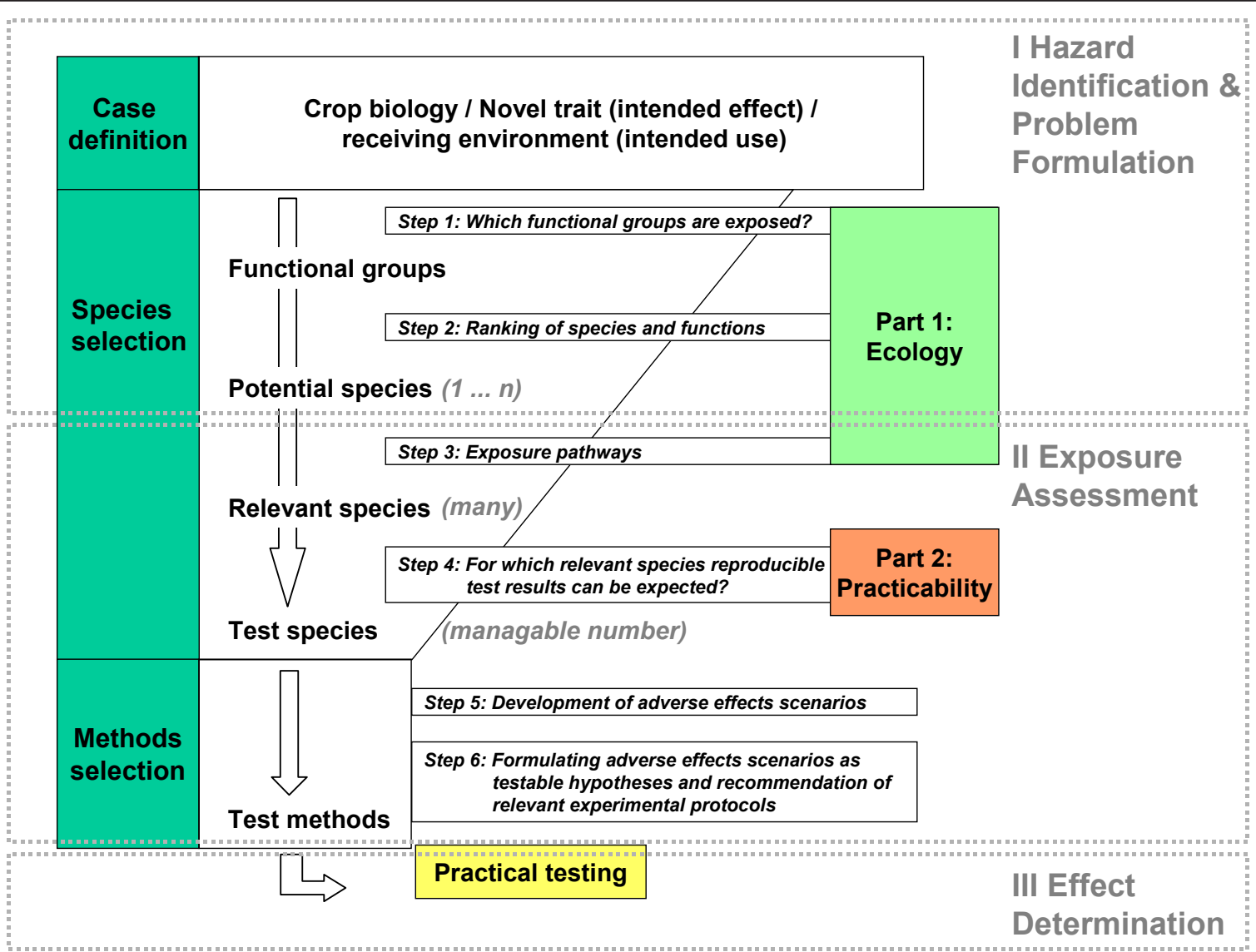

Figure 2 Scheme for selection of testing species and developing relevant testing protocols.

transgene products into the soil. Determination of the possible exposure pathways requires a solid characterization of the GM plant and the expressed novel traits and accompanying management systems. Hence, this step builds on and is only as good as the information collated in the previous component I. Because GM plants can multiply and spread via pollen and seed flow, this exercise will differ significantly from an exposure analysis of chemicals.

\section{Spread of transgene products/metabolites}

Currently, there exists little if any data on biogeochemical cycling, spread and fate of transgene products in the above- and below-ground ecosystems of the receiving environments and their potentially changing bioactivity and metabolites in the varying environmental media (e. g. different soils, composts, manures). Few studies published to date have confirmed the suspected spread of Bt-toxins through food chains in the agroecosystem [36-39]. Epigaeic predators (ground beetles of the genus Carabidae) collected in fields where Bt-crops had been grown two years before still contained Bt-toxin at a detectable level [37]. Bt-toxins from GM plants enter the ecosystem via many routes; embedded in living and decaying plant material, pollen or as toxin leaching and exudated from roots [40] and in faeces from insects and animals such as cows fed with Bt-maize feed $[41,42]$. However, the bioactivity of such metabolites remains unknown to date. Several experiments studied the impact of Bt-crop plant material on soil organisms with variable results ranging from some effects to transient effects to no effects $[43,44]$.

All of these studies focused on terrestrial agroecosystems. Only recently, the first papers were published that documented the input of transgene products or transgene DNA into aquatic systems, headwater streams and rivers [45] and connected them to possible adverse effects on some aquatic organisms [46,47]. Larger - and if possible coordinated - research and screening efforts are necessary to fully understand the spatio-temporal dimension of spread, persistence and bioactivity of the novel transgene products, like the Bt-toxins, and their metabolites embedded within or stemming from the GM plants in the various receiving ecosystems.

The information compiled in this component II will allow to further reduce the number of testing species 
from component I to those that are most exposed to GM plants and their transgene products/metabolites under the assumption that these will be the ones most likely experiencing adverse effects. Modelling exposure scenarios could assist in this effort.

\section{Adverse effect scenarios and testable hypotheses}

Understanding exposure routes and pathways of introduction of GM organisms and their transgene products into the environment is critically important to develop adverse effect scenarios and research hypotheses for the testing of the selected candidate species. We illustrate this using the three case examples of GM Bt-, HR- and starch-altered crops (Table 2). At the centre of the ERA under the broader model is always the whole plant including its transgene product(s) and intended effect(s) (Table 2).

For Bt-plants, as with any other plant compound, the novel toxic protein, like the Cry toxins of Bt-crops, must be expected to be ingested by almost all herbivores feeding on these crops and moving through the associated food chain. During this process, the novel protein can take on new properties as it is biochemically altered/broken down during the passage through the various gut milieus and may exert effects at higher trophic levels in an entirely unexpected way. Such effects cannot be predicted for example from the known mode of action stemming almost exclusively from a very restricted group of organisms, the target pest herbivores [48].

For GM HR crops, the stressor is the GM plant that triggers a secondary stressor, the application of broad spectrum herbicides like glyphosate or glufosinate. The use of these herbicides that were registered a long time ago can differ significantly in conjunction with HR crops from its conventional use and may give rise to adverse effect scenarios beyond and above those under its conventional use (see Farm Scale Evaluations) [49].

In the starch-altered GM crops, primary compound composition will be substantially if not radically altered compared to their conventional counterparts. For example, amylose synthesis is down-regulated close to nil while amylopectin production is up-regulated and constitutes the almost sole starch component in such a GM crop. Altered primary metabolism (e.g. starch) must also be expected to affect the food chain associated with these GM plants [50]. In the ecological and entomological scientific literature evidence for the mutual influence of plant compounds and herbivores on the evolution of both, the plants and their (pest) herbivores has been reported [50,51].

Experiments are necessary to deliver solid data that confirm or refute predicted routes of exposure,

Table 2 Illustrative classifications for types of properties, stressors, adverse effect scenarios and testable hypotheses

\begin{tabular}{|c|c|c|c|}
\hline GM crop & Bt crop & HR crop & Starch-altered crop \\
\hline \multirow{2}{*}{$\begin{array}{l}\text { Property } \\
\text { causing } \\
\text { adverse } \\
\text { effects }\end{array}$} & Property: insect resistance & Property: herbicide resistance & Property: altered starch composition \\
\hline & Mechanism: expression of toxin & Mechanism: Expression of altered EPSPS & $\begin{array}{l}\text { Mechanism: down- and up-regulation of } \\
\text { existing compounds }\end{array}$ \\
\hline \multirow[t]{4}{*}{$\begin{array}{l}\text { Stressor/ } \\
\text { mechanism }\end{array}$} & $\begin{array}{l}\text { Primary: Bt-crop and Bt toxin as integral } \\
\text { component }\end{array}$ & $\begin{array}{l}\text { Primary: HR-crop and altered EPSPS protein } \\
\text { as integral component }\end{array}$ & Primary: \\
\hline & & & High amylopectin content \\
\hline & & & No amylose content \\
\hline & Secondary: none & Secondary: Herbicide & Secondary: none \\
\hline $\begin{array}{l}\text { Adverse } \\
\text { effect } \\
\text { scenario }\end{array}$ & $\begin{array}{l}\text { Increased mortality of a chrysopid predator } \\
\text { feeding on an unaffected plant hopper in Bt } \\
\text { maize leads to reduced biocontrol and } \\
\text { higher plant hopper infestation }\end{array}$ & $\begin{array}{l}\text { Reduction of the local population of a } \\
\text { butterfly species whose larvae feed } \\
\text { monophagously on a certain nontarget } \\
\text { weed plant occurring mainly in oilseed } \\
\text { rape fields. }\end{array}$ & $\begin{array}{l}\text { Increased suitability of amylopectin GM } \\
\text { potato for a virus-transmitting aphid. More } \\
\text { aphids will now transmit more viruses and } \\
\text { create problems for neighbouring crop } \\
\text { plants. }\end{array}$ \\
\hline \multirow[t]{2}{*}{$\begin{array}{l}\text { Testable } \\
\text { hypotheses }\end{array}$} & $\begin{array}{l}\text { Higher generational mortality among } \\
\text { chrysopids raised on Bt maize-fed plant } \\
\text { hoppers }\end{array}$ & $\begin{array}{l}\text { Lower densities of caterpillars of the } \\
\text { particular butterfly species in fields treated } \\
\text { with the corresponding herbicide of the HR } \\
\text { oilseed rape than in non-GM oilseed rape } \\
\text { fields }\end{array}$ & $\begin{array}{l}\text { Higher reproduction rate and population } \\
\text { densities of aphids on amylopectin GM } \\
\text { potato than on non-GM isogenic potato }\end{array}$ \\
\hline & $\begin{array}{l}\text { Higher survival of plant hoppers on } \mathrm{Bt} \\
\text { maize than on isogenic maize in the } \\
\text { presence of a similar number of same-aged } \\
\text { chrysopid predators }\end{array}$ & & \\
\hline
\end{tabular}

The three case examples Bt-, HR- and starch-altered crops under a broader, alternative ERA model.

At the centre of the ERA is always the whole GM plant. 
bioactivity and to the extent possible, quantifies the exposure level (delivering basic data on transgene product metabolism and biological cycling). Developing adverse effect scenarios builds on the confirmed exposure routes of this component and the information compiled on the ecological function(s) of the candidate species in the previous component I. Please note, since only those candidate species have remained for this component that have an important ecological function, any adverse effect would be significant. Likewise, it may well be possible to eliminate a number of adverse effect scenarios already at this early stage if a critical exposure pathway can be proven to be non-existent or highly unlikely. For instance, if it can be determined that Bttoxins are not present in phloem and xylem sap of GM Bt-plants at this stage, a whole range of adverse effect scenarios arising from exposure of aphids, that feed exclusively on plant sap, and their associated food chain (s), including many important natural enemies, can be eliminated. Consequently, component II is critical for further reduction of the candidate testing organisms from Component I to those with the highest anticipated exposure. The outcome of this component II is a map of all identified exposure pathways and routes of spread of the GM crop plant, its transgenes and transgene products or the secondary stressors required for the realization of the benefit of the GM crop. To do this formally and in a transparent fashion, the use of the risk analysis tools called 'Event-Tree Analysis' and 'Fault-Tree Analysis' is recommended [52]. Fault- and Event-Tree Analyses are complementary tools used in risk assessment that were originally developed by engineers identifying critical steps in complex engineering processes, e.g. aviation or large scale industrial production facilities. In a modified form, they have been used for environmental purposes and different ecological systems [53-55]. While, fault-trees work 'top-down' beginning with a failure event (i.e. 'top-event'), event-trees work 'bottom-up' starting with an 'initiating event'. Both tools graphically lay out all of the parallel and sequential combinations of events that can lead to a particular 'top event' or arise from a particular 'initiating event'. This structured, logical approach allows to rigorously evaluate the potential of these events to occur based on scientific data and expert knowledge, and identifies what data and information is necessary to determine reliably the outcome and the gaps of knowledge associated with the possible events (Table 2).

\section{Effect determination - doing the testing and generating the data}

The main activity in component III of the ERA framework is the implementation of the testing plan developed in the two previous components (Figure 2). It corresponds in such directly to the provision for 'evaluation of the potential consequences of each adverse effect, if it occurs' of the Directive 2001/18/EC [2]. The aim is to measure whether the GM plant, it's intended (or perhaps anticipated unintended) use, or the transgene product can affect structural or functional endpoints. Testing should be carried out in a step-wise fashion $[2,3]$. The step-by-step principle means that the containment of genetically engineered organisms is reduced and the scale of release is increased gradually, moving from the laboratory to large-scale field testing in several steps provided the data obtained at the earlier steps give no reason for concern. This is because interactions with the environment can induce significant differences in evolutionary and ecological parameters for better or worse but certainly unpredictably.

However, again, controversy exists over whether the evidence for 'reason for concern' should be experimental (i.e. new original data produced) or could be extrapolated from theory and experience in related fields of science $[8,9,56-58]$. Secondly, whether or not an absence of a 'reason for concern' (i.e. evidence) constitutes evidence for safety to the effect that no more testing at higher levels is required $[12,58]$ is subject to debate. Here, we briefly outline the basic concept of our vision for hierarchical testing of GM plants depicted in Figure 3.

Especially, if significant uncertainties remain at one level - which is inevitably the case if only a small set of tests is carried out with surrogate proteins - it is necessary to proceed to the next level with caution. Given that GMOs can self-reproduce and spread, overlooked adverse effects can be difficult or impossible to recall once released into nature. As GM plants and their biochemical products can take on different properties in different environments and at different ecological organisational levels (e.g. when moving up the food chain, see above), data documenting/confirming the lack of evidence of adverse effects must be produced at every testing level (Figure 3). In contrast, if at a lower hierarchical level, i.e. laboratory or greenhouse, a high, difficult to manage adverse effect is determined, no further testing may be necessary if the GM plant will not pass the minimum safety requirements (Figure 3). However, failure criteria for environmental safety assessments of GM organisms have yet to be determined and examined in practice.

If data obtained at higher hierarchical levels do not support or confirm findings at lower hierarchical levels, additional laboratory testing with modified experimental protocols may be necessary to complete the scientific understanding of the functioning of the GM plant before moving to experiments at yet higher hierarchical levels with less or no confinement. Hence, our 


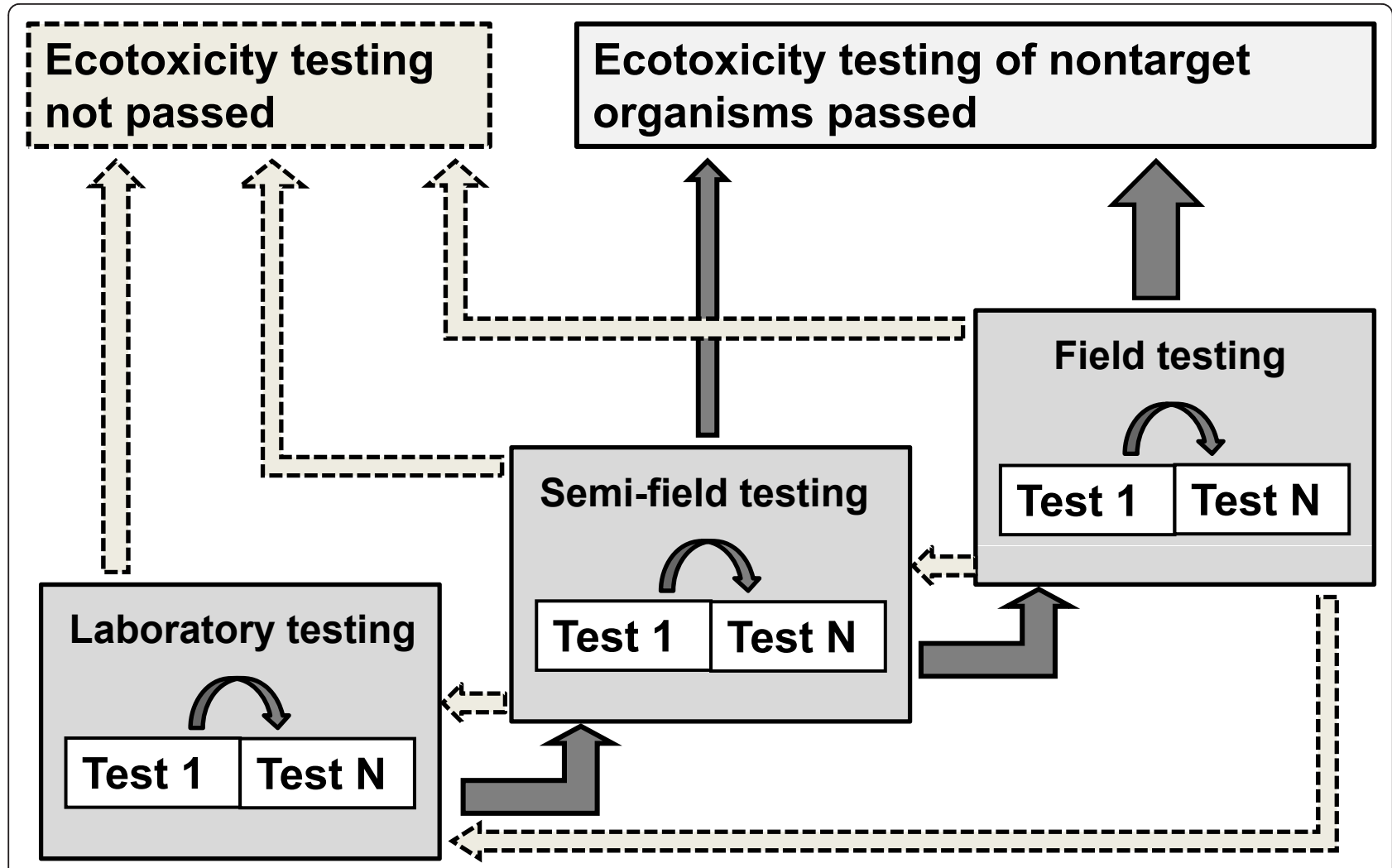

Figure 3 Proposed tiering scheme for ecotoxicological testing for environmental risk assessment of GM plants.

developed testing strategy is iterative and grounded in newly generated scientific data (Figure 3 ). The primary function of lower hierarchical level testing is to provide data that allows to focus and to inform the designing of experiments to be conducted at higher hierarchical levels. The testing strategy has to be driven by a coherent research risk hypothesis and strategy from the lowest to the highest tier of testing - a 'red thread' connecting the tiered testing programme is essential.

Risk characterization - synthesizing all information In this component of the ERA framework (Figure 1), the risk is characterised by combining and comparing the obtained data and information of the previous three components. While the emphasis is placed on quantitative data, all gathered qualitative information is also integrated here. This concurs with the provision of the 'estimation of the risk posed by each identified characteristic of the GMO(s)' put forward in the Directive 2001/18/EC [2]). If at a realistic exposure level, significant effects can occur, a risk for the environment is probable. Several outcomes are possible: A high to moderate risk can occur when a strong adverse effect occurs at a low or moderate exposure level, or, vice versa, when high exposure (i.e. extensive in space and time) induces a low to moderate adverse effect. Limited exposure and small adverse effects (e.g. low toxicity) can result in low risks, while the opposite is true when a strong effect coincides with high exposure.

The outcome of activities in this component is a list of potential risks with an estimation of their strength (high, moderate or low) that were experimentally confirmed. Rejected potential adverse effect hypotheses that could experimentally be proven as unlikely or minor or nonexistent are excluded. Equally important, the delimitation of the ERA and transparent documentation of remaining uncertainties is identified here. From this, guidance for possible risk management strategies and monitoring plans can be derived.

\section{Conclusions}

Despite over 10 years of large scale commercial production of GM crops in at least five countries, no consensus on the applied ERA methodologies, let alone agreed standardised testing procedures exist. Our proposed concept allows us to alleviate a number of deficits identified in the current approach to ERA of GM plants. Firstly, it integrates a procedure for selection of testing organisms in the formal risk assessment process that, for one, do occur in the receiving environment and, secondly, have an important role for those ecological functions that are critical for a sustainable production of the 
particular crop. Further, by devising a selection procedure that is embedded in the components of ERA, it optimally supports the decision making process. In our approach, only those species will be subjected to testing that end up being ranked highest regarding their importance for fundamental ecological functions in that crop and the greatest likelihood of significant exposure. Hence, observed adverse effects would constitute a biologically and ecologically meaningful result of concern that merits further investigation or surveillance. Further, since the GM plant is at the centre of the testing programme, all possible effects, direct and indirect, cumulative and interaction effects are included, thus, complying with the provision of the EU regulations [2,3]. Additionally, as science-based risk hypotheses and testing protocols are both derived from the selection procedure of testing organism, it also meets the call for hypothesisdriven testing regimes [59] and for 'a method to select the most important problems' [60]. Developing and ranking adverse effect scenarios and formulating testable risk hypotheses are key elements of our approach. Further improvements of this concept should now be carried out in the course of its application to actual cases in an EU context.

However, we distinctly disagree with the proposal that ERA of GMOs could be entirely a desk exercise based on 'data collected for other purposes' and may not require the 'acquisition of new data' as put forward by developers $[59,60]$. This leads to the current situation that new GM maize cultivars combining and stacking different Bt toxins by conventional crossing of various GM maize varieties enter the market largely untested. A case in point is the new Bt-maize event called 'Smartstax' that was recently registered for environmental release in the USA and Canada [61,62]. This GM maize combines six insecticidal Bt-toxins and resistance genes for two broad-spectrum herbicides and entered the market with close to no testing for toxic or environmental impacts relying entirely on 'the environmental risk assessment of the individual events' - except for one additional study with an unspecified non-target organism, the results of which are not even summarised [62]. In our view, this is not science based, lacks the required precaution and entirely puts the discovery of any potential adverse interaction, cumulative, indirect and longterm effect of the combined potpourri of six toxins and two herbicide residues on human and animal health and the environment in the marketing phase, i.e. the farmer and consumer. In contrast and consistent with the currently still prevailing interpretation of the ERA requirements, the developers did deliver data on target effects but almost none on non-target organisms. Just as no developer could possibly construct and deliver a reliably efficacious GM organism (i.e. deliver the benefits) based on 'data collected entirely for other purposes' or without 'new data' for and with that particular GM organism, its environmental biosafety cannot be demonstrated without 'new data'. The same ecological and biological principles that preclude the former do so for the latter.

\section{Acknowledgements}

This project was supported by the German Federal Agency for Nature Conversation (BfN) Research \& Development Grant No. 80564 005, Title 'Analysis and validation of present ecotoxicological test methods and strategies for the risk assessment of GMPs'

\section{Author details}

${ }^{1}$ Ecostrat GmbH, 8032 Zurich, Hottingerstrasse 32, Zurich, 8032, Switzerland ${ }^{2}$ Research Institute of Organic Agriculture (FiBL), Ackerstrasse, 5070 Frick, Switzerland ${ }^{3} \mathrm{ECT}$ Oekotoxikologie GmbH, Böttgerstrasse 2-14, Flörsheim, 65439, Germany ${ }^{4}$ Bundesamt für Naturschutz, Konstantinstrasse 110, Bonn, 53179, Germany

\section{Authors' contributions}

All authors contributed equally to the manuscript. All authors read and approved the final manuscript.

\section{Competing interests}

The authors declare that they have no competing interests.

Received: 3 February 2011 Accepted: 15 March 2011

Published: 15 March 2011

\section{References}

1. CBD: Cartagena Protocol on Biosafety to the Convention on Biological Diversity: Text and Annexes. Montreal: Secretariat of the Convention on Biological Diversity; 2000.

2. EC: Directive 2001/18/EC of 12 March 2001 on the deliberate release into the environment of genetically modified organisms and repealing Council Directive 90/220/EC, 17.4.2001, Official Journal of the European Communities L 106/1-38 2001.

3. EC: Commission Decision 2002/623/EC of 24 July 2002 establishing guidance notes supplementing Annex II to Directive 2001/18/EC of the European Parliament and of the Council on the deliberate release into the environment of genetically modfied organisms and repealing Council Directive 90/220/EEC, 30.7.2002, Official Journal of the European Communities L 200/22-33 2002.

4. Council of the European Union: Environment Council conclusions on genetically modified organism (GMOs). 29 12th Environment Council Meeting, Brussels 2008 [http://www.consilium.europa.eu/ueDocs/cms_Data/docs/ pressdata/en/envir/104509.pdf].

5. EurActive: Commission hesitant to approve more GM crops 2008 [http:// www.euractiv.com/en/environment/commission-hesitant-approve-gmcrops/article-172209;].

6. EFSA: Guidance document of the Scientific Panel on Genetically Modified Organisms for the risk assessment of genetically modified plants and derived food and feed. The EFSA Journal 2006, 99:1-100.

7. Mendelsohn M, Kough J, Vaituzis A, Matthews K: Are Bt crops safe? Nature Biotechnology 2003, 21:1003-1009.

8. Garcia-Alonso M, Jacobs E, Raybould A, Nickson Th, Sowig P, Willekens H, van der Kouwe P, Layton R, Amijee F, Fuentes AM, Tencalla F: A tiered system for assessing the risk of genetically modified plants to nontarget organisms. Environmental Biosafety Research 2006, 5:57-65.

9. Romeis J, Bartsch D, Bigler F, Candolfi MP, Gielkens MMC, Hartley SE, Hellmich RL, Huesing JE, Jepson PC, Layton R, Quemada H, Raybould A, Rose RI, Schiemann J, Sears MK, Shelton AM, Sweet J, Vaituzis Z, Wolt JD: Assessment of risk of insect-resistant transgenic crops to nontarget arthropods. Nature Biotechnology 2008, 26:203-208.

10. FAO/WHO: Biotechnology and food safety. Report of a joint Food and Agriculture Organization/World Health Organization Consultation Rome, Italy: FAO/WHO; 1996

11. OECD: Report of the task force for the safety of novel foods and feeds. C(2000) 86/ADD1 Organization for Economic Cooperation and Development, Paris 2000. 
12. Romeis J, Meissle M, Bigler F: Reply. Nature Biotechnology 2007, 25:36-37.

13. Dolezel M, Hilbeck A, Miklau M, Eckerstorfer M, Heissenberger A, Gaugitsch H: Standardisation of Environmental Risk Assessment for Genetically Modified Organisms (GMO) in the EU. Federal Agency for Nature Conservation Bonn - Bad Godesberg: BfN-Skripten 259; 2009.

14. Millstone EP, Brunner EJ, Mayer S: Beyond 'substantial equivalence'. Nature 1999, 401:525-526

15. Royal Society of Canada: Elements of precaution: recommendations for the regulation of food biotechnology in Canada Ottawa: Royal Society of Canada; 2001,245

16. Freese W, Schubert D: Safety testing and regulation of genetically modified engineered foods. Biotechnology and Genetic Engineering Reviews 2004, 21:299-324.

17. Romeis J, Meissle M, Bigler F: Reply. Nature Biotechnology 2006, 24:751-753.

18. Baird DJ, Maltby L, Greig-Smith PW, Douben PET, ECOtoxicology: Ecological Dimensions London: Chapman \& Hall; 1996.

19. Chapman PM: Integrating toxicology and ecology: putting the 'eco' into ecotoxicology. Marine Pollution Bulletin 2002, 44:7-15.

20. Forbes VE, Calow P: Extrapolation in ecological risk assessment: Balancing pragmatism and precaution in chemicals controls legislation. BioScience 2002, 52:249-257.

21. Hilbeck A, Jänsch S, Meier M, Römbke J: Analysis and validation of present ecotoxicological test methods and strategies for the risk assessment of genetically modified plants. In Federal Agency for Nature Conservation. Volume 236. Bonn - Bad Godesberg: BfN-Skripten; 2008:287.

22. Environmental Protection Agency (EPA): Monsanto; Pesticide Tolerance Petition Filing. Federal Register 1996, 61(248):67804-67807.

23. Arregui MC, Lenardon A, Sanchez D, Maitre Ml, Scotta R, Enrique S: Monitoring glyphosate residues in transgenic glyphsate-resistant soybean. Pest Management Science 2003, 60:163-166.

24. Cerdeira AL, Duke SO: The current status and environmental impacts of glyphosate-resistant crops: a review. Journal Environmental Quality 2006, 35:1633-1658.

25. Andow DA, Hilbeck A: Science-based risk assessment for non-target effects of transgenic crops. Bioscience 2004, 54:637-649.

26. Birch ANE, Wheatley R, Anyango B, Arpaia S, Capalbo D, Getu Degaga E, Fontes E, Kalama P, Lelmen E, Lövei G, Melo IS, Muyekho F, Ngi-Song A, Ochiendo D, Ogwang J, Pitelli R, Sétamou M, Sithanantham S, Smith J, Van Von N, Songa J, Sujii E, Quang Tan T, Wan FH, Hilbeck A: Biodiversity and non-target impacts: Case study of Bt-maize in Kenya. In Environmental Risk Assessment of Transgenic Organisms Volume 1: A Case Study of Bt Maize in Kenya. Edited by: Hilbeck A, DA Andow. Oxon: CABI Publishing; 2004.

27. Hilbeck A, Andow DA, Birch ANE, Fitt G, Johnston J, Nelson K, Osir E, Songa J, Underwood E, Wheatley R: Nontarget and Biodiversity Assessment: Methodologies and Framework. In Environmental Risk Assessment of Transgenic Organisms, Volume 2: A Case Study of Bt Cotton in Brazil. Edited by: Hilbeck A, Fontes E, DA Andow. Oxon, CABI Publishing; 2006.

28. Hilbeck A, Fontes E, Andow DA, (Eds): Environmental Risk Assessment of Transgenic Organisms, Volume 2: A Case Study of Bt Cotton in Brazil Oxon: CABI Publishing; 2006.

29. Hilbeck A, Andow DA, Arpaia S, Birch ANE, Chen Y, Fontes E, Fitt G, Lang A, Thi Thu Hong Le, Lövei G, Manachini B, Nguyen Cuc Thi Thu, Van Huynh Nguyen, Van Tuat Nguyen, Van Lam Pham, Van Toan Pham, Pires C, Sujii E, Trac Lai Khuong, Underwood E, Wheatley R, Wilson L, Zwahlen C: Non-target and Biological Diversity Risk Assessment. In Environmental Risk Assessment of Genetically Modified Organisms, Volume 4: Challenges and Opportunities with Bt Cotton in Vietnam. Edited by: Andow DA, Hilbeck A, Nguyen Van Tuat. Wallingford: CABI Publishing; 2008.

30. Hilbeck A, Nelson K, Andow DA, Underwood E: Problem Formulation and Options Assessment (PFOA) to Assess the Ecological Risks Associated with a GM Crop. Risk, Hazard, Damage - Specification of Criteria to Assess Environmental Impact of Genetically Modified Organisms. In Naturschutz und Vielfalt Edited by: Breckling, B, Verhoeven R 2004, 1:131-143

31. Nelson KC, Kibata G, Muhammad L, Okuro JO, Muyekho F, Odindo M, Ely A, Waquil JM: Problem formulation and options assessment (PFOA) for genetically modified organisms: the Kenya case study. In Environmental Risk Assessment of Transgenic Organisms, Volume 1: A Case Study of Bt Maize in Kenya. Edited by: Hilbeck A, Andow DA. Oxon: CABI Publishing; 2004:57-82.
32. Nelson KC, Banker MJ: Problem formulation and options assessment handbook A publication of the GMO ERA Project at; 2007 [http://www. gmoera.umn.edu], free download.

33. OECD (Organisation for Economic Cooperation and Development): Guidelines for the testing of chemicals, Paris, France (including all updates until today) 1981.

34. Andow DA, Hilbeck A, Van Tuat Nguyen, (Eds): Environmental Risk Assessment of Genetically Modified Organisms, Volume 4, Challenges and Opportunities with Bt Cotton in Vietnam Wallingford: CABI Publishing; 2008.

35. Hilbeck A, Andow DA, (Eds): Environmental Risk Assessment of Transgenic Organisms, Volume 1: A Case Study of Bt Maize in Kenya Oxon: CABI Publishing; 2004

36. Harwood JD, Wallin WG, Obrycki JJ: Uptake of Bt-endotoxins by nontarget herbivores and higher order arthropod predators: molecular evidence from a transgenic corn agroecosystem. Molecular Ecology 2005, 14:2815-2823.

37. Zwahlen C, Andow DA: Field evidence for the exposure of ground beetles to Cry $1 \mathrm{Ab}$ from transgenic corn. Environmental Biosafety Research 2005, 4:113-117.

38. Obrist LB, Dutton A, Albajes R, Bigler F: Exposure of arthropod predators to Cry1Ab toxin in Bt maize fields. Ecological Entomology 2006, 31:143-154.

39. Harwood JD, Samson RA, Obrycki Jj: Temporal detection of Cry1Abendotoxins by coccinellid predators in fields of Bacillus thuringiensis corn. Bull Entomol Res 2007, 97:643-648.

40. Saxena D, Stotzky G: Insecticidal toxin from Bacillus thuringiensis is released from roots of transgenic Bt corn in vitro and in situ. FEMS Microbiology Ecology 2000, 33:35-39.

41. Raps A, Kehr J, Gugerli P, Moar WJ, Bigler F, Hilbeck A: Immunological analysis of phloem sap of Bacillus thuringiensis corn and of the nontarget herbivore Rhopalosiphum padi (Homoptera: Aphididae) for the presence of CrylAb. Molecular Ecology 2001, 10:525-533.

42. Lutz B, Wiedemann S, Einspanier R, Mayer J, Albrecht C: Degradation of $\mathrm{Cry} 1 \mathrm{Ab}$ protein from genetically modified maize in the bovine gastrointestinal tract. Journal of Agricultural and Food Chemistry 2005, 53:1453-1456.

43. Zwahlen C, Hilbeck A, Howald R, Nentwig W: Effects of transgenic Bt corn litter on the earthworm Lumbricus terrestris. Molecular Ecology 2003, 12:1077-1086.

44. Blackwood CB, Buyer JS: Soil microbial communities associated with Bt and non-Bt corn in three soils. Journal of Environmental Quality 2004, 33:832-836.

45. Douville $M$, Gagné F, Blaise C: André C: Occurrence and persistence of Bacillus thuringiensis (Bt) and transgenic $\mathrm{Bt}$ corn cry1 Ab gene from an aquatic environment. Ecotoxicology and Environmental Safety 2007, 66:195-203.

46. Rosi-Marshall EJ, Tank JL, Royer TV, Whiles MR, Evans-White M, Chambers C, Griffiths NA: Toxins in transgenic crop byproducts may affect headwater stream ecosystems. Proceedings of the National Academy of Sciences of United States of America (PNAS) 2007, 104:16204-16208.

47. Bøhn T, Primicerio R, Hessen DO, Traavik T: Reduced fitness of Daphnia magna fed a Bt-transgenic maize variety. Archives of Environmental Toxicology and Chemistry 2008.

48. Hilbeck A, Schmidt JEU: Another view on Bt-proteins - how specific are they and what else might they do? Biopesticides International 2006, 2:1-50.

49. Hawes C, Haughton AJ, Osborne JL, Roy DB, Clark SJ, Perry JN, Rothery P, Bohan DA, Brooks DR, Champion GT, Dewar AM, Heard MS, Woiwod IP, Daniels RE, Young MW, Parish AM, Scott RJ, Firbank LG, Squire GR: Responses of plant and invertebrate trophic groups to contrasting herbicide regimes in the Farm Scale Evaluations of genetically-modified herbicide-tolerant crops. Philosophical Transactions of the Royal Society of London B 358 2003, 1439:1899-1913.

50. Berenbaum MR: Turnabout is fair play: Secondary roles for primary compounds. Journal of Chemical Ecology 1995, 21:925-940.

51. Scheirs J, de Bruyn L, Verhagen R: Host nutritive quality and host plant choice in two grass miners: primary roles for primary compounds? Journal of Chemical Ecology 2003, 29:1373-1389.

52. National Research Council (NRC): Environmental Effects of Transgenic Plants: The Scope and Adequacy of Regulation Washington, DC: National Research Council, National Academy Press; 2002.

53. Hayes KR: Ecological risk assessment for ballast water introductions: A suggested approach. ICES Journal of Marine Science 1998, 55:201-212. 
54. Hayes KR: Identifying Hazards in Complex Ecological Systems. Part 1: Fault-tree Analysis for Biological Invasions. Biological Invasions 2003, 4:235-249.

55. Hilbeck $A$, Meier M, Benzler A: Identifying indicator species for postrelease monitoring of genetically modified, herbicide resistant crops. Euphytica 2008, 164:903-912.

56. Andow DA, Zwahlen C: Assessing environmental risks of transgenic plants. Ecology Letters 2005, 9:196-214.

57. Andow DA, Lövei G, Arpaia S: Ecological risk assessment for Bt crops. Nature Biotechnology 2006, 24:749-751.

58. Lang A, Lauber E, Darvas B: Early-tier tests insufficient for GMO risk assessment. Nature Biotechnology 2007, 25:35-36.

59. Raybould A: Problem formulation and hypothesis testing for environmental risk assessments of genetically modified crops. Environmental Biosafety Research 2006, 5:119-125.

60. Raybould A: Ecological versus ecotoxicological methods for assessing the environmental risks of transgenic crops. Plant Science 2007, 173:589-602.

61. AGBIOS GM Database: 2009 [http://www.agbios.com/dbase.php? action $=$ ShowProd\&data $=$ MON89034 $+x+$ TC1507 $+x+$ MON88017+x+DAS59122-0037], MON-89Ø34-3 x DAS- Ø15Ø7-1 x MON-88Ø17-3 x DAS-591 (MON89034 x TC1507 x MON88017 x DAS-59122-7).

62. EPA Environmental Protection Agency OPPTS 7501P: Pesticide Fact Sheet 2009 [http://www.agbios.com/docroot/decdocs/09-211-001.pdf].

doi:10.1186/2190-4715-23-13

Cite this article as: Hilbeck et al:: Environmental risk assessment of genetically modified plants - concepts and controversies. Environmental Sciences Europe 2011 23:13.

\section{Submit your manuscript to a SpringerOpen ${ }^{\mathcal{O}}$ journal and benefit from:}

- Convenient online submission

- Rigorous peer review

- Immediate publication on acceptance

- Open access: articles freely available online

- High visibility within the field

- Retaining the copyright to your article

Submit your next manuscript at $\gg$ springeropen.com 